\title{
Metabolic Activity of Micromycetes Affecting Urban Concrete Constructions
}

\author{
Galina Yakovleva ${ }^{\mathbb{D}},{ }^{1}$ Eugene Sagadeev, ${ }^{2}$ Viktor Stroganov, ${ }^{2}$ Olga Kozlova, ${ }^{1}$ \\ Rodion Okunev, ${ }^{1}$ and Olga Ilinskaya ${ }^{1}$ \\ ${ }^{1}$ Institute of Fundamental Medicine and Biology, Kazan (Volga Region) Federal University, 420008 Kazan, \\ Kremlevskaya Str., 18, Russia \\ ${ }^{2}$ Kazan State University of Architecture and Engineering, 420043 Kazan, Zelenaya Str., 1, Russia \\ Correspondence should be addressed to Galina Yakovleva; yakovleva_galina@mail.ru
}

Received 23 August 2018; Accepted 6 November 2018; Published 2 December 2018

Academic Editor: Sanjay Govindwar

Copyright (C) 2018 Galina Yakovleva et al. This is an open access article distributed under the Creative Commons Attribution License, which permits unrestricted use, distribution, and reproduction in any medium, provided the original work is properly cited.

\begin{abstract}
Concrete resistance to the destructive action of microorganisms is considered as a measure of its durability and is increasingly being raised as an important issue. We focused our study on the biodeterioration of concrete specimens widely used as a building material of urban houses by micromycetes isolated from the inner wall surface of the former military hospital in Kazan city, Tatarstan, Russia. Fungal community consists of 9 Penicillium isolates, 6 Aspergillus, 2 Trichoderma, and 1 isolate of Alternaria. First, we have identified two dominant isolates, Aspergillus fumigatus and Penicillium brevicompactum, and characterized their destructive properties according to the radial growth rate, antagonistic activity towards bacterial habitants of concrete, and production of organic acids. Then, we have demonstrated that five tested brands of high-strength concrete differ in bioreceptivity. The alterations in concrete resistances to compression and flexure after fungal attack were recorded at the trend level, mainly due to a short exposure time of concrete to fungal destructors in tests recommended by national Russian standard. Finally, using scanning electron microscopy we have shown that colonization of concrete by the dominant fungi includes their penetration into the thickness of concrete and germination in cracks. Elementary analysis revealed the decrease of calcium content on about $41 \%$ after fungal growth on the concrete in liquid phase and on $32 \%$ by superficial growth in comparison with the samples without fungal treatment.
\end{abstract}

\section{Introduction}

Concrete, a mixture of Portland cement and water, aggregates and in some cases admixtures is a building material that gains strength over time. Biogenic deterioration of the concrete traditionally referred to microorganisms. The causes of building material biodeterioration are three main processes: mechanical, assimilative (building materials are a source of nutrition and energy for microorganisms), and dissimilative (the interaction of building materials with aggressive metabolites of microorganisms) [1]. The action of microorganisms on concrete structures can be classified according to their effects on concrete surfaces, concrete matrices and on cracking and crack growth [2]. The growth effects are supplemented by chemical action of microbial metabolites leading to the alteration of physicochemical properties of concrete materials and accelerating the destruction process [3]. The influence of microorganisms on concrete mainly occurs by eroding a concrete surface. This leads to an increase in the porosity of concrete, the appearance of cracks, chips, and other damage, which ultimately significantly reduces the life of this material [4]. The favorable conditions for microbial growth on the concrete surfaces are increased humidity (i.e., between $60 \%$ and 98\%), long-term cycles of wetting and drying, freezing and thawing, high concentration of carbon dioxide, high concentration of $\mathrm{Cl}^{-}$or $\mathrm{SO}_{4}{ }^{2-}$ ions, and a small amount of acids [5]. Biodeterioration of concrete structures was demonstrated to be a common occurrence; however, various microbial populations and mechanisms were shown to play different roles at different locations [6]. We focused our study on the biodeterioration of concrete specimens widely used as a building material of urban houses. 
Many buildings are believed to have been damaged to varying degrees by microbiologically induced destruction of concrete. Until today, there is no clear understanding of the extent and severity of the damage, the operative mechanism, and effective remedial techniques for the microbial attack to concrete structures [7]. There is a set of investigations describing concrete biodeterioration in tropical coastal and marine areas [8,9], Coombes, 2016, but little is known about this process in cities located in temperate-continental climate zones. Biologically influenced corrosion of concrete in big cities has most often been detected in building foundations and walls. Taken into account the absence of direct contacts of the city buildings with groundwater and low winter temperatures, the role of nonsporeforming and sporeforming but thermophilic sulfate-reducing bacteria (genus Desulfotomaculum) in destruction of houses is minimal. The basic destructors in this area are micromycetes synthesizing broad spectrum of organic acids which can be extremely aggressive to concrete [10]. Moreover, production of secondary metabolites (antibiotics, mycotoxins) gives them an advantage in the concrete colonization over bacteria.

Our study is aimed at isolation and identification of filamentous fungi growing on the concrete walls of old buildings in Kazan city (Tatarstan, Russia) and characterization of their destructive properties based on the measurement of growth rate and acid production, for the future assessment of deterioration level of fine-grained concrete induced by them. Applying an integrated approach combining methods of microbiology with standard methods for determining the strength of building structures, we justified the connection between the decrease of concrete strength and the level of fungal metabolic activity whose main markers were production of organic acids, radial growth rate, and antagonistic activity.

\section{Materials and Methods}

2.1. Micromycetes. The microscopic fungi were isolated from the inner wall surface of the former military hospital in Kazan city (Tatarstan, Russia). The surface of the concrete wall with visible growth of micromycetes at 10 different sites was treated with a sterile cotton swab, which was then placed in a tube with $5 \mathrm{ml}$ of sterile water. From there, 10 samples of $100 \mathrm{ml}$ (in triplicates) were applied to a solid Czapek-Dox medium in Petri dishes, which were incubated for 5 days at $30^{\circ} \mathrm{C}$. The morphology of colonies was analyzed microscopically. Total number of isolates was 18. The dominant fungi of the genera Aspergillus and Penicillium were used to study their destructive properties. For the cultivation of micromycetes, a liquid and agarized Czapek-Dox medium was used (g/l): $\mathrm{NaNO}_{3}$ - 2.0; $\mathrm{KH}_{2} \mathrm{PO}_{4}$ - 1.0; $\mathrm{MgSO}_{4} \times 7 \mathrm{H}_{2} \mathrm{O}-0.5 ; \mathrm{KCl}$ - 0.5; $\mathrm{FeSO}_{4}$ - 0.01; sucrose - 30.0; $\mathrm{H}_{2} \mathrm{O}-1000 \mathrm{ml}$. Microscopic identification of dominant fungi was supplemented by Sanger sequencing of ITS (internal transcribed spacer) regions of the isolates using standard primers ITS1 and ITS 4 [11]. Variable ITS1 and ITS2 sequences which are located in the ribosomal operon between the small (SSU) and the large subunit (LSU) sequences surrounding the $5.8 \mathrm{~S}$ rRNA gene were analyzed and compared with those of reference strains downloaded from MycoBank and GenBank databases.
2.2. Concrete Specimens and Their Treatment by Fungi. High strength sandy concrete samples M 400, M 500, M 600, M 800 , and M 1000 were made in the form of beams with a size of $160 \times 40 \times 40 \mathrm{~mm}$. In the manufacture of cementsand mortars based on Portland cement grades PC400 and PC500 (strength corresponding to classes B30 and B40) and concretes of classes $\mathrm{B} 45, \mathrm{~B} 60$, and $\mathrm{B} 70$ the ratio of sand (fraction 0.5-0.25 mm corresponding to Russian state standard GOST 8736-93) and cement was three to one. In the manufacture of concrete class B45, B60, and B70 (M 600, M 800, and M 1000) based on Portland cement PC500, Melflux 2651 F superplasticizer (BASF Construction Polymers) was added in an amount of $0.5 \%$ by weight of cement (Mordovcement, Russia). The water/cement ratio was $53 / 100$. For universality of notation, hereinafter we use the term "cement" for all samples. The strength of concrete is specified by the marks denoted by the Latin letter " $M$ " and by numbers from 400 to 1000 , depending on the amount of cement used in a mix and indicating the compressive strength in $\mathrm{kg} / \mathrm{cm}^{2}$. The prepared sterile beams were placed in containers presterilized with $70 \%$ ethanol (Figure 1(a)). Containers were filled with a sterile medium, and spores of dominant micromycetes $\left(10^{5} / \mathrm{ml}\right)$ were added (Figures $1(\mathrm{~b})$ and $1(\mathrm{c})$ ). Control container was filled by sterile Czapek-Dox medium without inoculation. The lower part of the beams up to a height of $2 \mathrm{~cm}$ was immersed in the medium; the upper part was in the humid atmosphere of the closed containers which were incubated at $30^{\circ} \mathrm{C}$ during 28 days.

2.3. Organic Acids Analysis. Cultural fluid of 18 fungal isolates growing 5 days up to the end of exponential phase on liquid Czapek-Dox medium was analyzed on the production of secreted organic acids using a high-performance liquid chromatograph Flexar (PerkinElmer, USA). The separation of organic acids was carried out in a Brownlee Analytical C18 $(150 \times 4.6 \mathrm{~mm})$ column packed with $3 \mu \mathrm{m}$ particles. The elution was carried out at room temperature in a linear gradient using a system consisting of a solution of $10 \mathrm{mM}$ $\mathrm{KH}_{2} \mathrm{PO}_{4}$ adjusted with orthophosphoric acid to $\mathrm{pH} 2.4$ (eluent A) and acetonitrile (eluent $\mathrm{B}$ ).The flow rate of the mobile phase was $1 \mathrm{ml} / \mathrm{min}$. Peaks were identified using a UV detector at $210 \mathrm{~nm}$ [12]. As standards, acid solutions were used (g/l): oxalic (0.15), tartaric (0.35), malic (0.5), lactic (0.35), citric (0.5), and acetic (0.15).

2.4. Determination of Micromycete Radial Growth Rate. The rapid growth rate of fungi is connected with the production of organic acids as primary metabolites. To found the most active fungal isolates, the determination of micromycete radial growth rate (RGR) was performed. The colony diameter of isolates on agar medium was measured each $24 \mathrm{~h}$ in eight mutually perpendicular directions; arithmetic mean was taken at each time-point. The RGR was calculated according to the formula: $\operatorname{RGR}=\left(\mathrm{r}-\mathrm{r}_{\mathrm{o}}\right) /\left(\mathrm{t}-\mathrm{t}_{\mathrm{o}}\right)$, where $\mathrm{r}_{\mathrm{o}}$ is the radius of the colonies at the initial time $t_{o}$ and $r$ is the radius of the colonies at the time $t$.

2.5. Antagonistic Activity Assay. Secondary metabolites producing at stationary growth phase are not involved directly 


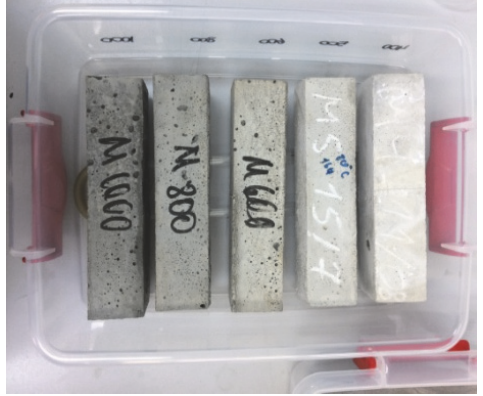

(a)

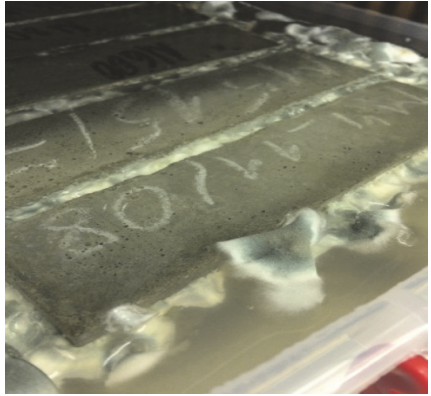

(b)

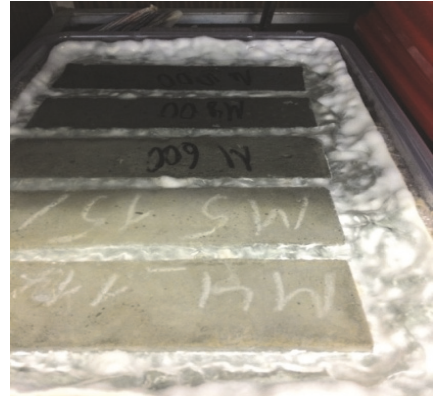

(c)

Figure 1: Concrete specimens of different marks (M300, M400, M600, M800, and M1000), untreated, indicating the location of samples before covering by the medium (a) and treated by Aspergillus fumigatus A2 (b) and Penicillium brevicompactum P4 (c) spores after 5 days of fungal growth. The photos were performed after opening the containers, and the covers were removed. The signs on the beams correspond to the tested brands of concrete.

in the normal growth and development of the fungus, but they play an important role in ecological interactions with other organisms. To characterize the ability of fungi to produce some aggressive secondary metabolites contributing to inhibition of bacterial community growth on concrete and indirectly affect the destruction of concrete, the antagonistic activity of micromycetes towards isolated bacterial community was determined by the agar block method. Flushing water from the concrete surface was added to LB medium and cultivated for 24 hours to obtain the mixed bacterial culture. The micromycete isolates A2 and $\mathrm{P} 4$ were cultured for 10 days on the Czapek-Dox agar. Then, agar blocks with growing fungi were cut with a sterile plug drill and transferred to the surface of the Czapec-Dox agar, freshly seeded with a bacterial culture, and incubated for 2 days at $28^{\circ} \mathrm{C}$. The antagonistic activity was measured by the size of bacterial growth inhibition zone.

2.6. Concrete Stability Assay. Compressive and flexural strengths are measured by breaking concrete specimens in special hydraulic press and are calculated as failure load divided by cross-sectional area (reported in megapascals, $\mathrm{MPa}$ ). Compressive and flexural strengths were tested before and after exposure to growing mycromycetes as described earlier [13].

2.7. Scanning Electron Microscopy. Concrete samples were washed, fixed by glutaraldehyde (if fungal growth was found), dehydrated with ethanol and dried at room temperature. Before microscopy samples were coated with gold/palladium. The determination of the element composition and visualization of concrete surface structure were carried out using scanning electron microscopy (Carl Zeiss Merlin with energy dispersion Spectrometer AZtec X-MAX, Germany). Surface morphology was analyzed at an accelerating voltage of 5 $\mathrm{keV}$. Elemental analysis was carried out at an accelerating voltage of $20 \mathrm{keV}$ and a working interval of $9 \mathrm{~mm}$. A set of Aztec program standards (reference standards for X-RAY microanalysis "Registered Standard No. 8842") was used.

2.8. Statistics. Mathematical processing of data was carried out using standard computer program Excel 7.0. All experiments were carried out in at least three replicates. The data group was considered homogeneous if the root-meansquare deviation $\sigma$ in it did not exceed $12 \%$.

\section{Results}

3.1. Analysis of Isolated Mycromycetes and Their Organic Acids. We have isolated 18 micromycetes from the inner walls of the old hospital building in Kazan city and found that fungal communities represented the class Eurotiomycetes and family Trichocomaceae. Predominant genera $(83 \%)$ were filamentous fungi Penicillium (9 isolates) and Aspergillus (6 isolates). Micromycetes of the genera Alternaria (1 isolate) and Trichoderma ( 2 isolates) were found to be minor representatives.

Figure 2 demonstrates the metabolic activity of micromycetes after 5 days of cultivation according to the production of organic acids. The 15 investigated isolates, excluding Alternaria and Trichoderma, are able to synthesize oxalic acid. Malic acid was found in cultural fluid of 14 micromycetes, acetic acid was synthesized by 10 isolates, citric - by 9 , lactic - by 5 , and tartaric acid-by two isolates (Figure 2(a)). Oxalic acid, when contacted with the concrete surface, forms a complex of calcium oxalate which has a low solubility and therefore contributes to the formation of a protective layer on the concrete surface which promotes the preservation and strengthening of concrete structure, as well as diminishing of microcracks formation [14]. Nonsoluble calcium tartrate could have the same consequences. The acetic, lactic, and malic acids did not form the nonsoluble salts and thus are more aggressive towards concrete structures. Calcium citrate is slightly soluble in water and freely soluble in diluted acids, especially at lower temperatures (so-called "inverse solubility") [15]. When calcium citrate has shown crystalline precipitate formation, it has been attributed to the salt's superior solubility over that of calcium carbonate formed by contact with carbon dioxide as calcite tightly associated with concrete surface (Figure 3(a)). In this regard, to study the effect of organic acids on concrete stability we selected micromycetes synthesizing the greatest amount of citric acid. 


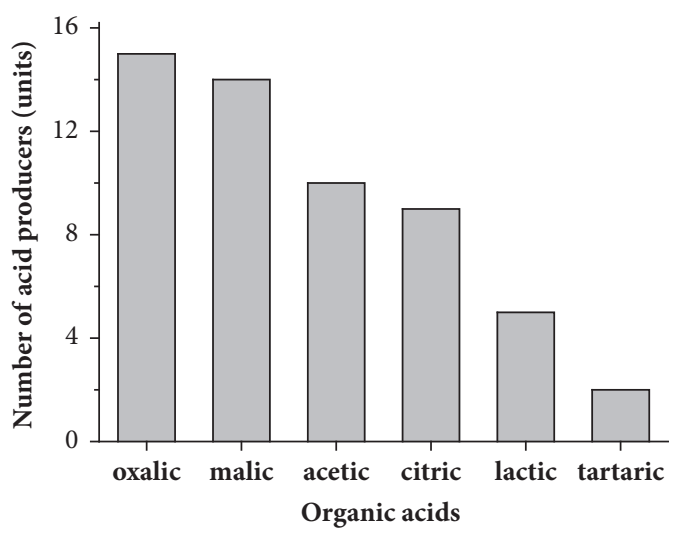

(a)

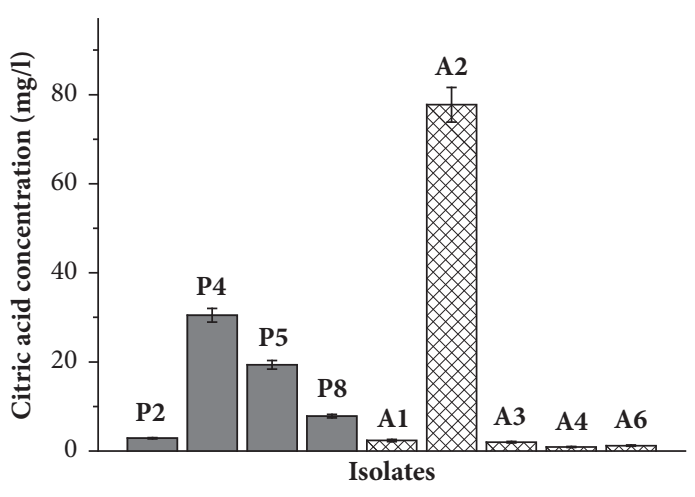

(b)

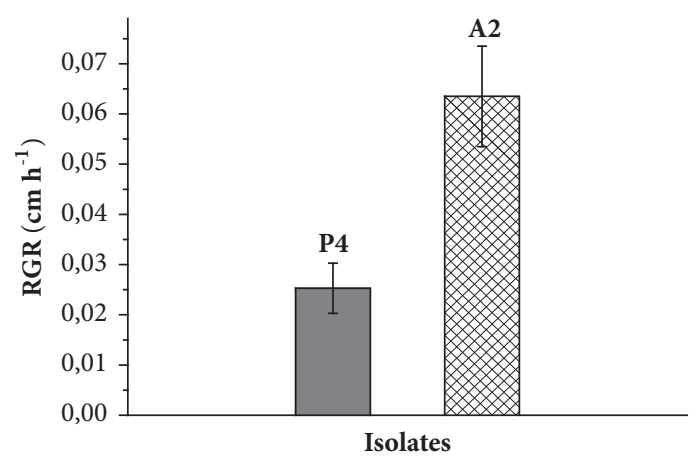

(c)

FIGURE 2: Metabolic activity of micromycetes after 5 days of cultivation. (a) The number of isolates synthesizing different organic acids; (b) the amount of citric acid produced by Aspergillus isolates (marked with letter A) and Penicillium isolates (marked with letter P); (c) radial growth rate of two dominant isolates, A. fumigatus $\mathrm{A} 2$ and P. brevicompactum $\mathrm{P} 4$.

Of the nine isolates capable of synthesizing citric acid four isolates belonged to the genus Penicillium (P1, P2, P3, and P4) and five to the genus Aspergillus (A1, A2, A3, A4, and A6) (Figure 2(b)). The maximum amount of citric acid among these isolates was produced by Aspergillus A2 (77.74 $\mathrm{mg} / \mathrm{l})$. Despite the fact that this A2 isolate had the highest concentration of citric acid in the culture liquid, the percentage ratio of citric acid among all other produced organic acids (their joint content was taken for $100 \%$ ) was only $12.5 \%$. The maximum percentage ratio of citric acid $(29.0 \%$, corresponds to $30.47 \mathrm{mg} / \mathrm{l}$ ) was detected for Penicillium P4. Based on this data and the measured values of RGR (Figure 2(c)) we selected two isolates identified as $A$. fumigatus A2 and $P$. brevicompactum $\mathrm{P} 4$ for the treatment of concrete samples. ITS region sequences are represented in Supplementary.

3.2. Characterization of Micromycete Growth and Antagonistic Activity. Already on the $5^{\text {th }}$ day of the experiment, growth of A. fumigatus A2 and P. brevicompactum $\mathrm{P} 4$ on the all concrete samples was appeared (Figures 1(b) and 1(c)). The growth of A. fumigatus A2 was significantly more intensive than the growth of $P$. brevicompactum $\mathrm{P} 4$ confirming the belonging of A2 isolate to r-strategists. R-strategists have concurrent characteristics based on the ability to rapidly occupy a new habitat [16]. According to RGR and full spectra of produced acids, the most aggressive were both the strains A. fumigatus $\mathrm{A} 2$ and the P. brevicompactum P4, wherein the strain A2 possessed the highest RGR (Figure 2(c)) and P4 strain had the highest antagonistic activity against bacterial community isolated from the same walls of the old hospital building (Figure 4).

\subsection{Modification of Concrete Stability and Element Com-} position. Russian state standard (GOST 9.048-89: «Unified system of corrosion and ageing protection. Technical items. Methods of laboratory tests for mould resistance») recommended treating the samples by fungi during 28 days. After 28 days of contact with the strain A. fumigatus A2 and P. brevicompactum $\mathrm{P} 4$ in containers partially filled with medium, the values of concrete samples stability were determined. As it can be seen from Table 1, the coefficients of resistance to flexure $\left(\mathrm{R}_{\mathrm{f}}\right)$ and to compression $\left(\mathrm{R}_{\mathrm{c}}\right)$ after contact with the growing strains decreased by no more than $1 \%$ indicating that there are low changes in the concrete specimens strength. The minimal changes were also observed when the samples were incubated in medium without inoculation (Table 1). However, these changes increase over time and gradually contribute to the deterioration of concrete. Penetration of $P$. brevicompactum P4 into the thickness of concrete and germination in cracks was established using scanning microscopy (Figure 3). The same results were obtained for A. fumigatus A2 (data not 

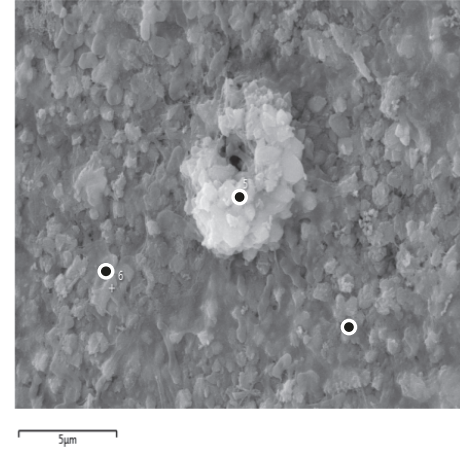

(a)

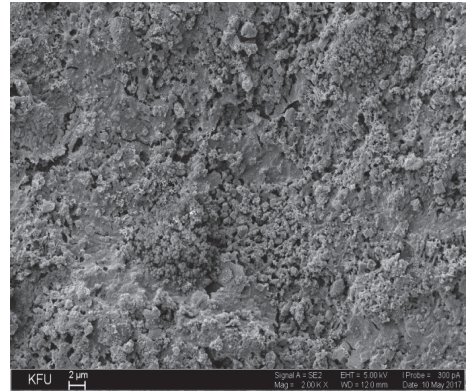

(d)

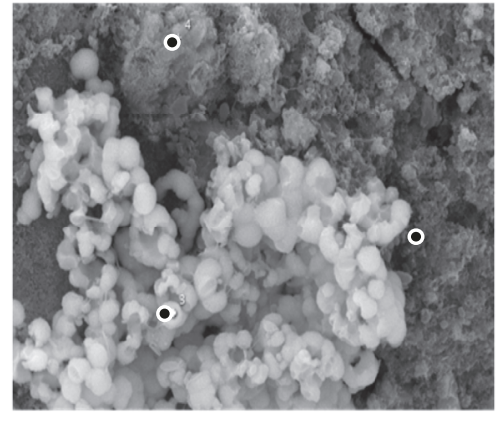

(b)

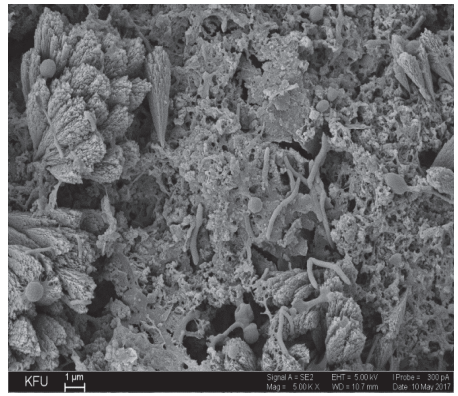

(e)

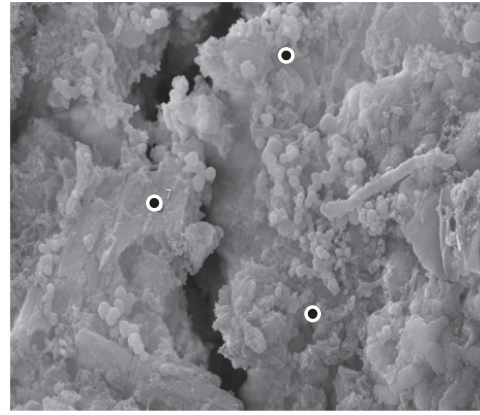

(c)

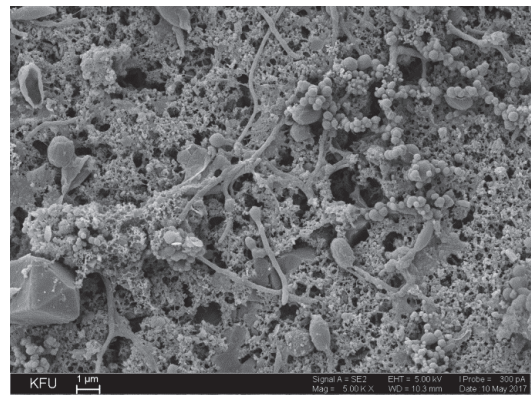

(f)

Figure 3: Visualization of M 600 concrete samples surface infected by P. brevicompactum P4 spores after 28 days of treatment. (a, d) Control samples without treatment; (b, e) fungal growth on the concrete surface which was completely immersed in the culture medium; (c, $\mathbf{f})$ superficial growth on the concrete surface which was contacted with air in container. (a-c) Samples used for element composition testing, points show areas for analysis (Merlin scanning microscope, Carl Zeiss, Germany). (a) Illustration of chemical formation of calcite around the microcrack.

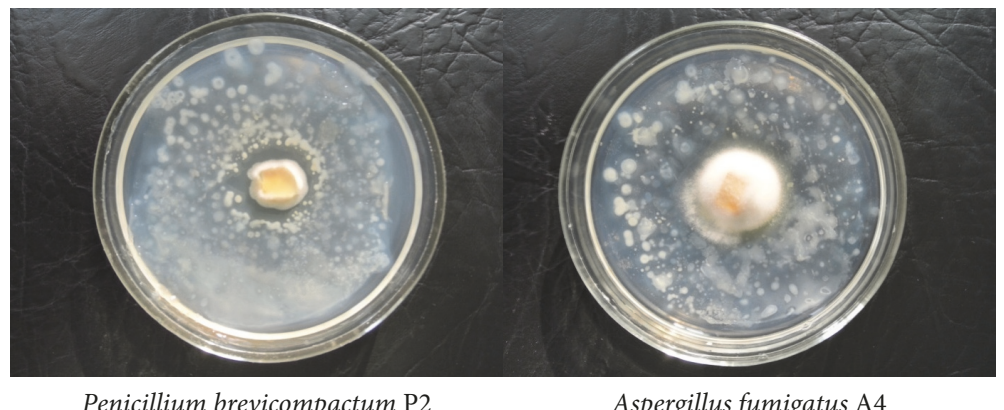

Figure 4: Antagonistic activity of micromycetes towards the bacterial community. The transparent zone around the agar block appearing after 2 days of incubation at $28^{\circ} \mathrm{C}$ reflects the inhibition of bacterial growth by secreted secondary metabolites of fungi.

shown). It should be noted that fungal growth on the surface of concretes which were completely immersed to a depth of 5 $\mathrm{cm}$ in the culture medium (Figures $3(\mathrm{~b})$ and $3(\mathrm{e})$ ) was more intensive compared to superficial one at the border with air (Figures 3(c) and 3(f)). This fact was confirmed by element analysis of concrete surface samples. As can be seen from Figure 5, the decrease of calcium content on about $41 \%$ after fungal growth on the concrete in liquid phase was slightly higher than this decrease (32\%) by superficial growth. No significant changes in the content of other elements were found.

\section{Discussion}

4.1. Isolates from Buildings Differ from Listed in Recommendations for Biostability Testing. The reason for the concrete destruction of city buildings is mainly the incorrect operating conditions, rather than the spontaneous effects of atmospheric precipitation. The lack of room ventilation, high humidity, a large crowd of people, and, finally, a long time of operation all cause a slow, but permanent destruction of concrete structures used for internal floors of residential buildings. That is why our research is aimed at identifying 
TABLE 1: Alteration of strength characteristics of concrete during 28 days of exposure in Czapek Dox medium without inoculation (CDM) and inoculated by spores of Aspergillus fumigatus A2 and Penicillium brevicompactum $\mathrm{P} 4$.

\begin{tabular}{|c|c|c|c|c|c|c|c|c|}
\hline \multirow{3}{*}{ Concrete specimens } & \multicolumn{8}{|c|}{ Characteristics of concrete strengths, $\mathrm{MPa}$} \\
\hline & \multicolumn{4}{|c|}{ Compressive strength, $\mathrm{R}_{\mathrm{c}}$} & \multicolumn{4}{|c|}{ Bending strength, $\mathrm{R}_{\mathrm{f}}$} \\
\hline & Initial & $\mathrm{CDM}$ & A2 & $\mathrm{P} 4$ & Initial & $\mathrm{CDM}$ & A2 & $\mathrm{P} 4$ \\
\hline M400 & 6.60 & 6.55 & 6.50 & 6.48 & 32.30 & 32.25 & 32.15 & 32.14 \\
\hline M500 & 7.10 & 7.05 & 7.00 & 7.00 & 42.80 & 42.75 & 42.65 & 42.60 \\
\hline M 600 & 9.50 & 9.45 & 9.40 & 9.40 & 60.80 & 60.72 & 60.70 & 60.69 \\
\hline M 800 & 10.50 & 10.49 & 10.40 & 10.42 & 74.80 & 74.80 & 74.70 & 74.65 \\
\hline M 1000 & 12.20 & 12.17 & 12.15 & 12.15 & 95.20 & 95.16 & 95.00 & 95.05 \\
\hline
\end{tabular}
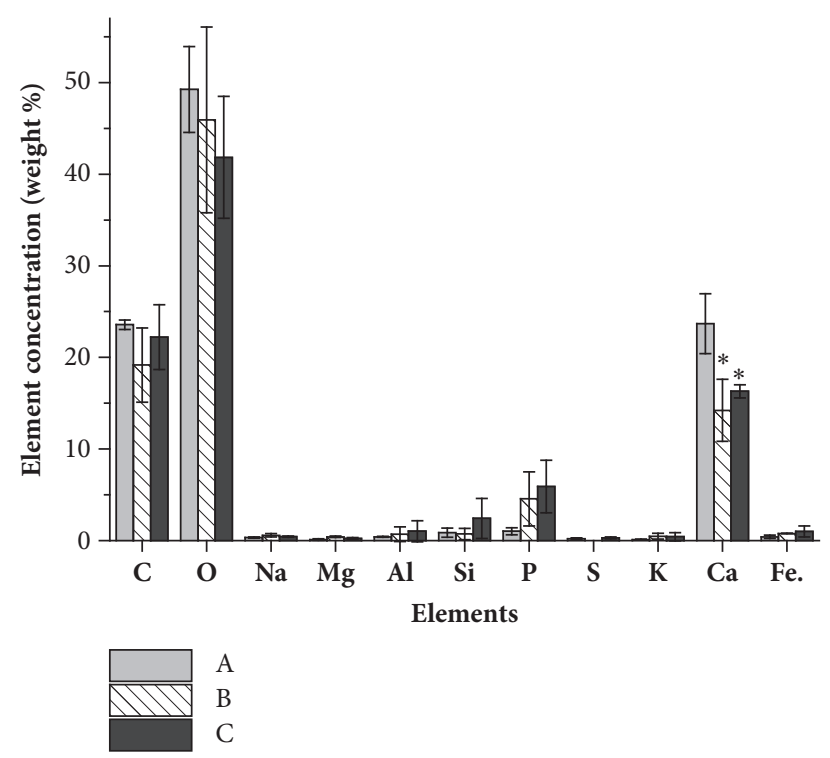

FIGURE 5: Content of elements in the surface layer of M 600 concrete. A: without treatment; B: surface which was completely immersed in the culture medium during 28days of P. brevicompactum $\mathrm{P} 4$ growth; C: concrete surface which was contacted with air in container during 28days of P4 growth. Each column represents mean measurement of three points located on the concrete surface shown in Figures $2(a)-2(c)$. Significant differences from option A $(p<0.05)$ are indicated by $*$.

microorganisms that destroy concrete in the real operating conditions of buildings. It was important to determine how different types of concrete used in construction are susceptible to biodeterioration and how standard tests to determine it reflect the real situation. To date, there are more than 200 different methods to test biostability of building materials. Along with international standards, there are national standards for individual countries (STD 141C/6271/2-86 for USA; BS 1133 for UK, DIN 53739-84 for Germany, NF X 41-514-81 for France; JIS Z 2911-87 for Japan, GOST 9.04889 for Russia). GOST 9.048-89 recommends the application of 8 different fungi (Aspergillus niger, Aspergillus terreus, Aureobasidium pullulans, Paecilomyces variotii, Penicillium funiculosum, Penicillium ochrochloron, Scopulariopsis brevicaulis, and Trichoderma viride) to test alteration of concrete strength. According to our data, the species isolated from the old building walls differ from recommended ones. This means that the biodeteriogen microorganisms are special for each particular building which they inhabit. Micromycetes isolated in this study mainly belong to the genera Aspergillus and Penicillium. The species identification was carried out for two more aggressive isolates, A. fumigatus A2 and $P$. brevicompactum $\mathrm{P} 4$, which were selected for analysis of their biodeteriogen activity towards concrete samples because of high level of primary metabolites synthesis (the amount of citric acid produced by A. fumigatus A2 was $77.74 \mathrm{mg} / \mathrm{l}$, and by $P$. brevicompactum $\mathrm{P} 4$ was $30.47 \mathrm{mg} / \mathrm{l}$ ), as well as because of high growth rate which provides the advantage in settling ecological niches compared to slow-growing microorganisms.

The main fungal genera detected on painted buildings over the 42-week period were Alternaria, Curvularia, Epicoccum, Helminthosporium, Coelomycetes (mainly Pestalotia/Pestalotiopsis), Monascus, Nigrospora, Aureobasidium, and Cladosporium [17]. A list of major strains in hospital environments (Centre F. Baclesse, Normandy, France) compiled according to their frequency, concentration level, and/or capacity to produce mycotoxins in vitro was as follows: $A$. fumigatus, A. melleus, A. niger, A. versicolor, Cladosporium herbarum, Purpureocillium lilacinum, and P.brevicompactum [18]. At this list there are two representatives (A. fumigatus and P. brevicompactum) which we have also isolated from the walls of old hospital in Kazan. So, it could be concluded that biodeteriogen fungi isolated from concrete walls of buildings completely differ from isolates from painted surfaces.

4.2. Organic Acids Spectra Play an Important Role in Concrete Biodeterioration. Adverse effects of geoactive fungi include biodeterioration of natural and synthetic materials, rock and mineral-based building materials (e.g., concrete), cultural heritage, metals, alloys, and related substances [19]. There are three key biological factors affecting the destruction of concrete in a certain building: the presence of fungal strains having a high growth rate and as a consequence dominating in the community (i); high level of produced organic acids, especially citric acid, whose salts with calcium do not form a protective film but provoke microcracks deepening (ii); significant antagonistic activity of certain fungi strains which allows them to displace bacterial communities inhabiting concrete items (iii). Because of the chemical nature of citric acid, it has the ability to react with the alkaline components of the concrete matrix to form calcium citrate. The chemical reaction of citric acid with the top layer of calcium hydroxide 
creates the etching of the concrete surface. As long as there is excess acid present, the calcium citrate will remain soluble. As the acid is consumed, the solubility decreases and the calcium citrate precipitates out as a solid, inducing microcracks deepening. All mentioned factors cannot be compared to well-known destructive activity of sulfate-reducing bacteria in sewage, where the sulfuric acid formed from hydrogen sulfide dissolves the carbonates in the cured cement and causes strength loss, as well as producing sulfates which are harmful to concrete [20]. They also at least in part differ from variable biological factors influencing buildings in a subtropical climate [21]. Today, biofouling and biodeterioration of concrete structures including underground structures, sewage systems, at-sea structures, and wastewater treatment systems has been examined [5]. Great attention is paid to biodeterioration of painted buildings $[17,22]$ and objects of cultural heritage [21, 23]. Unfortunately, there is not enough information on biodeterioration of concrete items of residential buildings in temperate and continental climate. From this point of view, our work provides the first data characterizing destructive properties of fungi inhabiting concrete in these conditions.

4.3. Loss of Calcium Leads to Concrete Strength Decrease. Calcium release and acid production were known to be important processes influencing concrete stability. We observed the decrease of calcium content after $P$. brevicompactum $\mathrm{P} 4$ growth on the concrete, which was higher in case of growth in liquid phase compared to the superficial growth (Figure 5). Fusarium species induced the same alteration of concrete. Nonbiological formation of $\mathrm{CaCO}_{3}$ in the reaction of air-born carbon dioxide with the calcium hydroxide in concrete was shown on the concrete surface which was not infected by fungi. Stable $\mathrm{CaCO}_{3}$ was precipitated in the pore system (Figure 3(a)). Carbonatation has two effects: it increases mechanical strength of concrete, but it also decreases alkalinity, which creates favorable conditions for fungi growth leading to the loss of calcium in concrete (Figure 5). The 15 fungal isolates identified in this study produced oxalic acid (Figure 2(a)) and therefore form calcium oxalate which creates a protective layer on the concrete surface contributing to positive impact of this acid production [14, 24]. A lower number of isolates producing lactic and malic acids which form more or less soluble calcium salts indicates their prevalent role in $\mathrm{pH}$ decrease which promotes the future development of fungi. Citric acid can be attributed to agents of negative influence on concrete because calcium citrate precipitates increasing microcracks size. The main conclusion that could be made from the results concerning fungal acid production is the ambiguity of the effect of various acids on concrete stability. In respect that the acid spectra of different strains are different, it is difficult to predict structure damage without studying the characteristics of specific destructors. For example, the study of marinegrade concrete colonized with barnacle indicates that barnacles do not enhance but likely reduce rates of mechanical breakdown on rock and concrete by buffering near-surface thermal cycling and reducing salt ion ingress [25]. Bacterial biomineralization can contribute to protection-consolidation of ornamental stone [26]. Of course, fungi cannot be related to agents of bioprotection, but their influence on concrete is not always obligatory negative and depends on certain acid production.

Here, we have found that standard test recommended for assessment of concrete biodamage characterized the differential lesion of different concrete marks at the trend level. Nevertheless, the compressive and flexural strengths of concrete specimen M 1000 retain less alerted in comparison to other concrete brands (Table 1). If we focus on these data, the higher content of cement in the concrete sample increases its resistance to fungal harm. It was shown that the ability of concrete to resist damaging influence of hydrochloric acid is due to the cement brand and its amount [27]. Because microorganisms cause both the initiation, as well as the intensification of concrete corrosion processes [10], probably, the testing time was not enough to detect more significant differences in alteration of concrete strength characteristics.

4.4. Fungal Toxins Contribute to Sick Building Syndrome. Finally, it must be noted that the colonization of building material by toxigenic fungi raises the question of the subsequent exposure of occupants to aerosolized mycotoxins. $P$. brevicompactum, commonly encountered in the indoor air and isolated at out study, is known to produce mycotoxins. There are the mycophenolic acid [28] and ochratoxin A which has carcinogenic, teratogenic, and nephrotoxic potential and sustains a high half-life in human blood [29]. The most part of the aerosolized toxic load is found in particles whose size corresponds to spores or mycelium fragments. However, some toxins were also found on particles smaller than spores that are easily respirable and can deeply penetrate into human respiratory tract [30] contributing to sick building syndrome which is considered to be a multifactorial health problem of the overwhelming majority of the population in cities [31]. The relevance of the concrete biodeterioration study itself and its consequences for the environment and human health is constantly increasing.

\section{Conclusion}

Biodeterioration of concrete widely used in residential city buildings has now become an important environmental problem. First at all, fungal deterioration of houses increases during the operation time and is hard to stop. Second, its consequences for human health must be taken into account, as, according to statistics, urban residents spend about $95 \%$ of their time indoors. Here, we have characterized the metabolic activity of dominant fungal habitants of old city building contributed to concrete biodetrioration, including radial growth rate, antagonistic activity, and production of organic acids. We have demonstrated that fungal growth induced calcium release from concrete surface. Decrease of calcium was higher if the concrete surface was located in liquid phase compared (41\%) to surface contacted with air (36\%). The alterations of the compressive and flexural strengths of concrete specimens depending on concrete brands were detected along with decrease of calcium content. The stability of concrete samples exposed to growing Aspergillus and 
Penicillium isolates during 28 days decreased on about 1\%.To detect real individual alterations of the concrete specimens induced by fungi, the duration of the recommended standard test has to be prolonged. The problem of concrete biodeterioration in city houses cannot be regarded as topsignificant today, but the time factor enhances its value. Special emphasis on variable fungal destructive activities, on complex mechanisms, and on a system for correct analysis of concrete deterioration all are areas in need of additional investigation.

\section{Data Availability}

The data used to support the findings of this study are available from the corresponding author upon request.

\section{Conflicts of Interest}

The authors declare that there are no conflicts of interest regarding the publication of this article.

\section{Acknowledgments}

This work was performed within the Program of Competitive Growth of Kazan Federal University. Equipment of the Interdisciplinary Center for Collective Use (ID RFMEFI59414X0003 and ID 327737) sponsored by the Ministry of Education and Science of the Russian Federation was used.

\section{References}

[1] D. Allsopp, K. J. Seal, and C. C. Gaylarde, Introduction to Biodeterioration, Cambridge University Press, 2nd edition, 2006.

[2] O. Aviam, G. Bar-Nes, Y. Zeiri, and A. Sivan, "Accelerated biodegradation of cement by sulfur-oxidizing bacteria as a bioassay for evaluating immobilization of low-level radioactive waste," Applied and Environmental Microbiology, vol. 70, no. 10, pp. 6031-6036, 2004.

[3] E. Bastidas-Arteaga, M. Sánchez-Silva, A. Chateauneuf, and M. R. Silva, "Coupled reliability model of biodeterioration, chloride ingress and cracking for reinforced concrete structures," Structural Safety, vol. 30, no. 2, pp. 110-129, 2008.

[4] M. Sanchez-Silva and D. V. Rosowsky, "Biodeterioration of construction materials: State of the art and future challenges," Journal of Materials in Civil Engineering, vol. 20, no. 5, pp. 352365, 2008.

[5] S. Wei, Z. Jiang, H. Liu, D. Zhou, and M. Sanchez-Silva, "Microbiologically induced deterioration of concrete: a review," Brazilian Journal of Microbiology, vol. 44, no. 4, pp. 1001-1007, 2013.

[6] R. Rogers, "Effects of Microbially Influenced Degradation on Massive Geothermal Field Concrete Structures," Corrosion Reviews, vol. 17, no. 3-4, 1999.

[7] S. Nasrazadani and E. Sudoi, "A Review of biodeterioration of concrete structures. ID NACE-10216. Publisher NACE International Source CORROSION 2010, 14-18 March," in ID NACE10216. Publisher NACE International Source CORROSION 2010, San Antonio, Texas, 2010, https://store.nace.org/3aalb8b42859-df11-a321-005056ac759b.
[8] P. K. Mehta, Concrete in the marine environment, Taylor \& Frances, 2005.

[9] M. R. Silva and T. R. Naik, "Biodeterioration of concrete structures in coastal zone," in Proceedings of the Third International Conference on Sustainable Construction Materials and Technologies, Kyoto Research Park, Kyoto, 2013, http://www.claisse.info/2013\%20papers/data/e418.pdf.

[10] B. Cwalina, "Biodeterioration of concrete," Architecture Civil Engineering Environment, vol. 4, pp. 133-140, 2008.

[11] K. J. Martin and P. T. Rygiewicz, "Fungal-specific PCR primers developed for analysis of the ITS region of environmental DNA extracts," BMC Microbiology, vol. 5, article no. 28, 2005.

[12] W. M. Reuter, The analysis of a broad range of organic acids by HPLC with UV detection: application brief. Shelton: PerkinElmer, 2015, https://www.perkinelmer.com/lab-solutions/ resources/docs/APP_Analysis-of-Chlorophenols-in-Water-byUHPLC-with-PDA-Detection-012442_01.pdf.

[13] G. Y. Yakovleva, A. R. Zajnullina, V. F. Stroganov et al., "Assessment of biodamage resistance of various concrete grades," International Journal of Pharmacy and Technology, vol. 8, no. 4, pp. 24291-24299, 2016, http://www.ijptonline.com/wp-content/ uploads/2017/01/24291-24299.pdf.

[14] V. F. Stroganov and E. V. Sagadeev, Biodeterioration of building materials, Construction Materials, Moscow, Russia, 2015.

[15] S. L. Goss, K. A. Lemons, J. E. Kerstetter, and R. H. Bogner, “ Determination of calcium salt solubility with changes in $\mathrm{pH}$ and $\mathrm{P}$," Journal of Pharmacy and Pharmacology, vol. 59, no. 11, pp. 1485-1492, 2007.

[16] M. Ijdo, N. Schtickzelle, S. Cranenbrouck, and S. Declerck, "Do arbuscular mycorrhizal fungi with contrasting life-history strategies differ in their responses to repeated defoliation?" FEMS Microbiology Ecology, vol. 72, no. 1, pp. 114-122, 2010.

[17] M. A. Shirakawa, C. C. Gaylarde, P. M. Gaylarde, V. John, and W. Gambale, "Fungal colonization and succession on newly painted buildings and the effect of biocide," FEMS Microbiology Ecology, vol. 39, no. 2, pp. 165-173, 2002.

[18] N. Heutte, V. André, C. Dubos Arvis et al., "Assessment of multicontaminant exposure in a cancer treatment center: a 2-year monitoring of molds, mycotoxins, endotoxins, and glucans in bioaerosols," Environmental Modeling \& Assessment, vol. 189, no. $1,2017$.

[19] G. M. Gadd, "The geomycology of elemental cycling and transformations in the environment," Microbiology Spectrum, vol. 5, no. 1, 2017.

[20] S. Okabe, M. Odagiri, T. Ito, and H. Satoh, "Succession of sulfuroxidizing bacteria in the microbial community on corroding concrete in sewer systems," Applied and Environmental Microbiology, vol. 73, no. 3, pp. 971-980, 2007.

[21] C. Gaylarde, J. A. Baptista-Neto, A. Ogawa, M. Kowalski, S. Celikkol-Aydin, and I. Beech, "Epilithic and endolithic microorganisms and deterioration on stone church facades subject to urban pollution in a sub-tropical climate," Biofouling, vol. 33, no. 2, pp. 113-127, 2017.

[22] D. J. Giannantonio, J. C. Kurth, K. E. Kurtis, and P. A. Sobecky, "Molecular characterizations of microbial communities fouling painted and unpainted concrete structures," International Biodeterioration \& Biodegradation, vol. 63, no. 1, pp. 30-40, 2009.

[23] T. C. Dakal and S. S. Cameotra, "Microbially induced deterioration of architectural heritages: Routes and mechanisms involved," Environmental Sciences Europe, vol. 24, no. 1, 2012. 
[24] M. O. Fomina, S. V. Olishevs'ka, V. M. Kadoshnikov, B. P. Zlobenko, and V. S. Pidhors'kyi, "Colonization and destruction of concrete by mitosporic fungi in model experiment," Mikrobiol Z, vol. 67, no. 2, pp. 96-104, 2005, https://www.ncbi.nlm.nih .gov/pubmed/16018222.

[25] M. A. Coombes, H. A. Viles, L. A. Naylor, and E. C. La Marca, "Cool barnacles: Do common biogenic structures enhance or retard rates of deterioration of intertidal rocks and concrete?" Science of the Total Environment, vol. 580, pp. 1034-1045, 2017.

[26] M. Gonzalez-Munoz, "Bacterial biomineralization applied to the protection-consolidation of ornamental stone: current development and perspectives," Coalition, vol. 15, pp. 12-18, 2008, http://www.rtphc.csic.es/issues/15_4.pdf.

[27] J. J. Sokołowska and P. Woyciechowski, "Effect of acidic environments on cement concrete degradation," in Proceedings of the Third International Conference on Sustainable Construction Materials and Technologies, Kyoto Research Park, Kyoto, Japan, 2013, http://www.claisse.info/2013\%20papers/data/e085.pdf.

[28] M. Ndagijimana, C. Chaves-López, A. Corsetti et al., "Growth and metabolites production by Penicillium brevicompactum in yoghurt," International Journal of Food Microbiology, vol. 127, no. 3, pp. 276-283, 2008.

[29] L. Kupski, M. Freitas, D. Ribeiro, E. B. Furlong, and E. Fernandes, "Ochratoxin A activates neutrophils and kills these cells through necrosis, an effect eliminated through its conversion into ochratoxin $\alpha$," Toxicology, vol. 368-369, pp. 91-102, 2016.

[30] B. Aleksic, M. Draghi, S. Ritoux et al., "Aerosolization of Mycotoxins after Growth of Toxinogenic Fungi on Wallpaper," Applied and Environmental Microbiology, vol. 83, no. 16, 2017.

[31] S. Joshi, "The sick building syndrome," Indian Journal of Occupational and Environmental Medicine, vol. 12, no. 2, p. 61, 2008. 


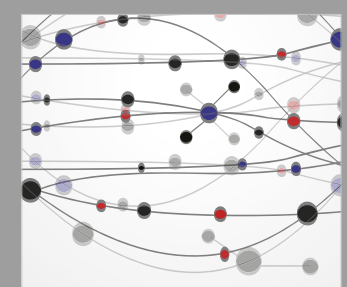

The Scientific World Journal
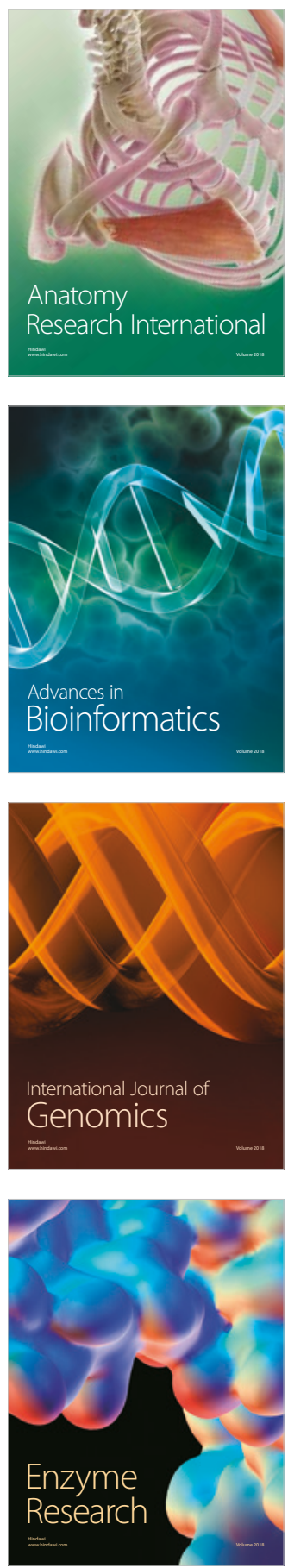
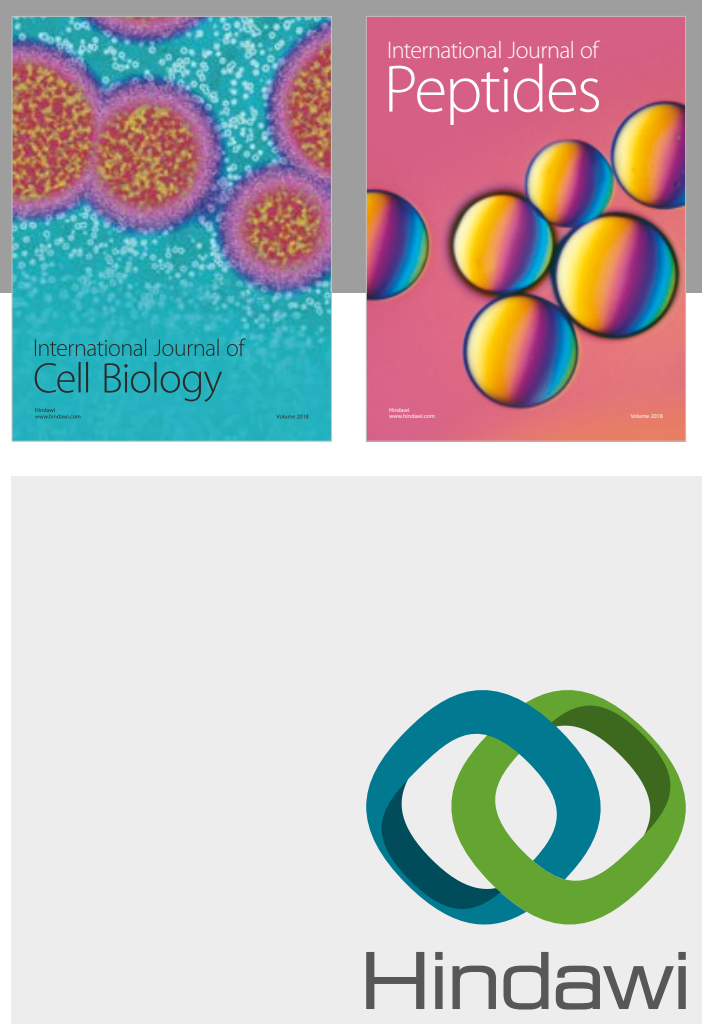

Submit your manuscripts at

www.hindawi.com
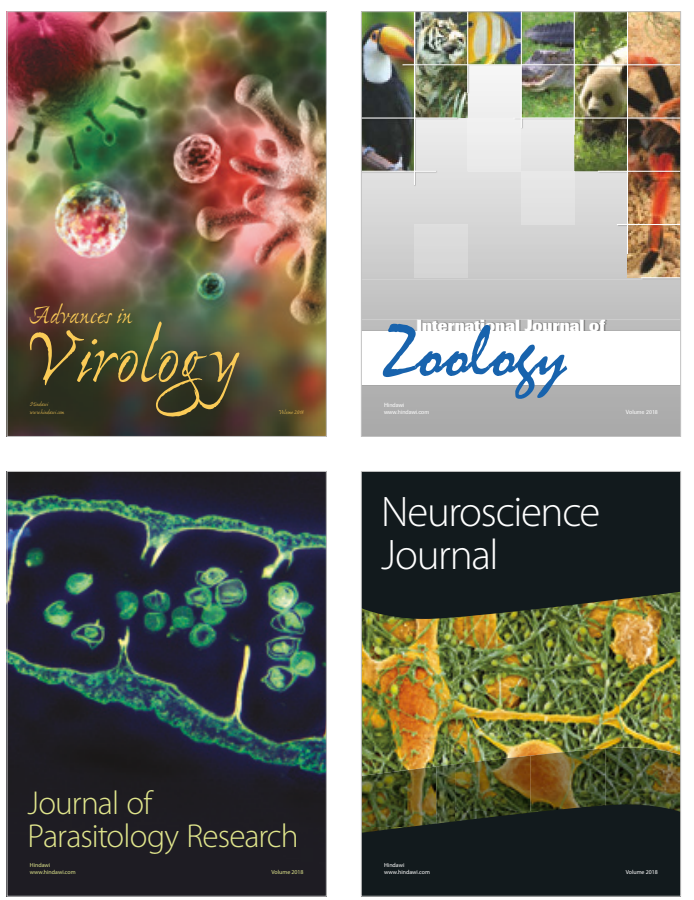
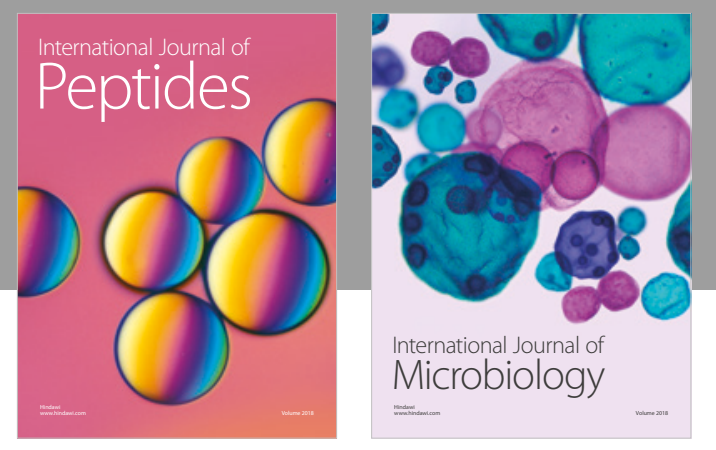

nternational Journal of Microbiology
Journal of
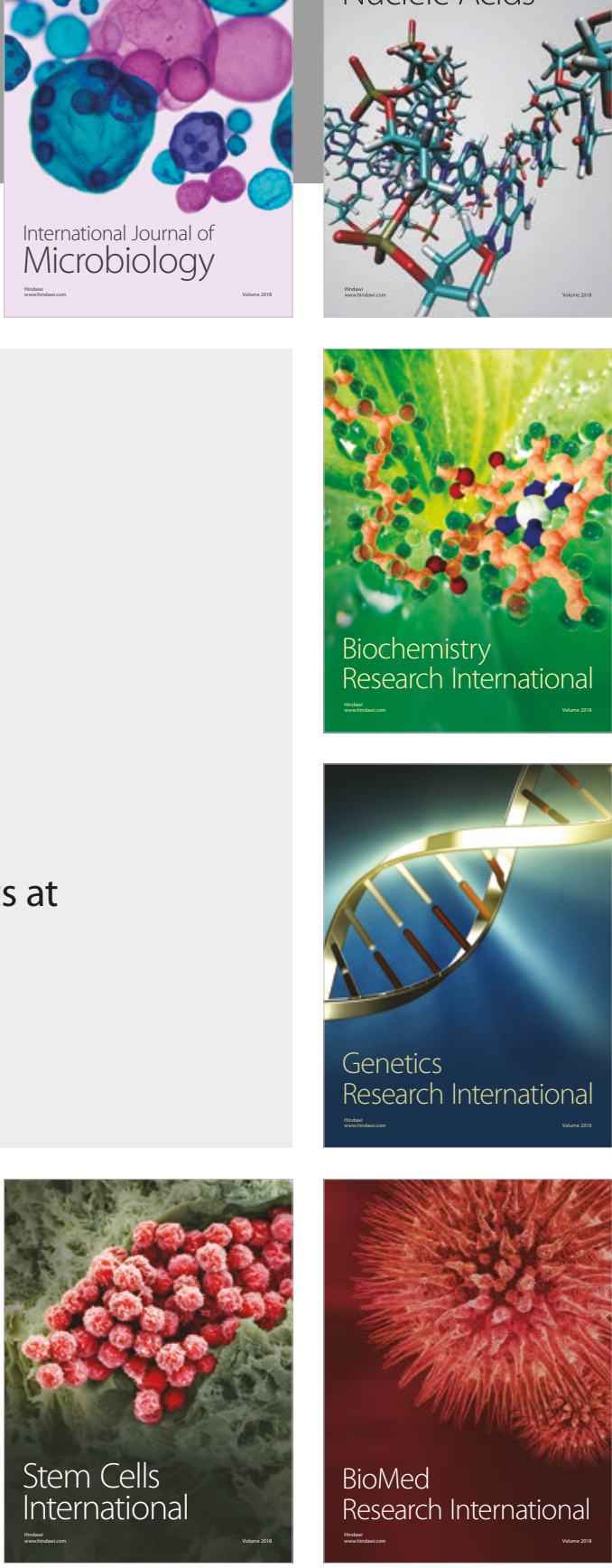
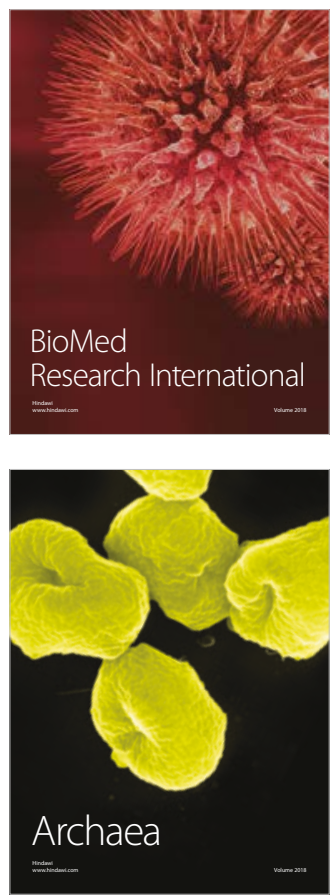